Acta Crystallographica Section B

Structural

Science

ISSN 0108-7681

Tomče Runčevski, ${ }^{a}$ Robert $\mathrm{E}$. Dinnebier, ${ }^{\mathrm{a} *}$ Oxana V. Magdysyuk $^{a}$ and Herbert Pöllmann ${ }^{b}$

aMax-Planck-Institute for Solid State Research, Heisenbergstraße 1, Stuttgart D-70569,

Germany, and ${ }^{\mathbf{b}}$ Institut für Geowissenschaften und Geographie, FG Mineralogie/Geochemie, Halle Von Seckendorff-Platz Haus 3, Halle D06120, Germany

Correspondence e-mail: r.dinnebier@fkf.mpg.de

\title{
Crystal structures of calcium hemicarboaluminate and carbonated calcium hemicarboaluminate from synchrotron powder diffraction data
}

One of the main phases formed at the beginning of the carbonation reaction of cementitious building materials is the calcium hemicarboaluminate (abbreviated as Hc). This AFm (shorthand for hydrated calcium aluminate phases structurally related to hydrocalumite) phase was synthesized, crystallized and then studied by synchrotron X-ray powder diffraction and micro-Raman spectroscopy. At room temperature and standard experimental conditions two major cementitious phases were detected, the $\mathrm{Hc}$ phase (as a major phase) and carbonated calcium hemicarboaluminate (abbreviated as $\mathrm{cHc}$ ). By increasing the temperature the Hc form transforms into cHc. The crystal structures of these important AFm phases were successfully solved and refined in the $R \overline{3} c$ space group of the trigonal crystal system. Hc has the unit-cell parameters $a=5.7757$ (1) and $c=48.812$ (2) $\AA$, and cHc the unit-cell parameters $a=5.7534$ (1) and $c=46.389$ (1) А. The two crystal structures are composed of positively charged main layers, $\left[\mathrm{Ca}_{4} \mathrm{Al}_{2}(\mathrm{OH})_{12}\right]^{2+}$, and negatively charged interlayers, $\left[\mathrm{OH}_{2 n}\left(\mathrm{CO}_{3}\right)_{1-n} \cdot 4 \mathrm{H}_{2} \mathrm{O}\right]^{2-}$. The structure of the main layers is typical of the AFm family. Conversely, the interlayer region has a characteristic structure built up from water molecules and statistically distributed anions. In the interlayer, the Hc carbonate and hydroxyl anions are distributed in a 0.25:0.5 ratio, whereas the ratio of the anions in the $\mathrm{cHc}$ interlayers is $0.4: 0.2$.

\section{Introduction}

Cements are one of the most used materials in the construction industry and civil engineering. Calcium aluminate cements (also known as aluminous or high-alumina cements) are of special interest because of their ability to develop rapid strength (even at low temperatures) and high chemical resistance. On hydration, they can form AFm phases (shorthand for hydrated calcium aluminate phases structurally related to hydrocalumite) which belong to the lamellar double hydroxide family (Pöllmann, 1984; Matschei et al., 2007). Carbonatecontaining AFm phases are mainly formed during the carbonation process of many different building materials. The AFm phases are composed of positively charged main layers and negatively charged interlayers. The main layers have a similar structure in all AFm phases, with the chemical formula $\left[\mathrm{Ca}_{4} \mathrm{Al}_{2}(\mathrm{OH})_{12}\right]^{2+}$, and are built up of aluminium octahedra and calcium capped trigonal antiprisms. Conversely, the interlayer region is characterized by pronounced diversity in the composition and structure, and can accommodate one (primary interlayer), two (binary) or three (tertiary) types of anions. In the AFm phases with a primary interlayer, $\left[X_{x} \cdot n \mathrm{H}_{2} \mathrm{O}\right]^{2-}, X$ can be carbonate (Fischer \& Kuzel, 1982; François et al., 1998; Renaudin, François et al., 1999; Renaudin
Received 29 May 2012

Accepted 3 July 2012
(C) 2012 International Union of Crystallography Printed in Singapore - all rights reserved 
Table 1

Crystallographic data of selected AFm phases (with structures solved in the trigonal crystal system, the most similar compounds to Hc and cHc are highlighted).

\begin{tabular}{|c|c|c|}
\hline Compound name and formula & $\begin{array}{l}\text { Space group and unit-cell } \\
\text { parameters }(\AA)\end{array}$ & Reference \\
\hline $\begin{array}{l}\text { Hemicarboaluminate } \\
{\left[\mathrm{Ca}_{4} \mathrm{Al}_{2}(\mathrm{OH})_{12}\right]\left[\mathrm{OH}\left(\mathrm{CO}_{3}\right)_{0.5} \cdot 4 \mathrm{H}_{2} \mathrm{O}\right]}\end{array}$ & $\begin{array}{l}R \overline{3} c \\
a=5.7757(1) \\
c=48.812(2)\end{array}$ & This work \\
\hline $\begin{array}{l}\text { Carbonated hemicarboaluminate } \\
{\left[\mathrm{Ca}_{4} \mathrm{Al}_{2}(\mathrm{OH})_{12}\right]\left[\mathrm{OH}_{0.4}\left(\mathrm{CO}_{3}\right)_{0.8} \cdot 4 \mathrm{H}_{2} \mathrm{O}\right]}\end{array}$ & $\begin{array}{l}R \overline{3} c \\
a=5.7534(1) \\
c=46.389(1)\end{array}$ & This work \\
\hline $\begin{array}{l}\text { Friedel's salt } \\
\text { (high-temperature phase) } \\
{\left[\mathrm{Ca}_{4} \mathrm{Al}_{2}(\mathrm{OH})_{12}\right]\left[2 \mathrm{Cl} \cdot 4 \mathrm{H}_{2} \mathrm{O}\right]}\end{array}$ & $\begin{array}{l}R \overline{3} c \\
a=5.755(2) \\
c=46.97(1)\end{array}$ & $\begin{array}{l}\text { Rapin } \text { et al. (2002) } \\
\text { Renaudin, Kubel et al. (1999) } \\
\text { Mesbah, Rapin et al. (2011) }\end{array}$ \\
\hline $\begin{array}{l}\text { Chloro-carboaluminate } \\
{\left[\mathrm{Ca}_{4} \mathrm{Al}_{2}(\mathrm{OH})_{12}\right]\left[\mathrm{Cl}\left(\mathrm{CO}_{3}\right)_{0.5} \cdot 4 \mathrm{H}_{2} \mathrm{O}\right]}\end{array}$ & $\begin{array}{l}R \overline{3} c \\
a=5.740(1) \\
c=46.74(1)\end{array}$ & $\begin{array}{l}\text { Mesbah, François et al. (2011); } \\
\text { Mesbah, Rapin et al. (2011) }\end{array}$ \\
\hline $\begin{array}{l}\text { Bromo-chloroaluminate } \\
{\left[\mathrm{Ca}_{4} \mathrm{Al}_{2}(\mathrm{OH})_{12}\right]\left[\mathrm{ClBr} \cdot 4 \mathrm{H}_{2} \mathrm{O}\right]}\end{array}$ & $\begin{array}{l}R \overline{3} c \\
a=5.7537(4) \\
c=48.108(4)\end{array}$ & $\begin{array}{l}\text { Rapin \& François (2001) } \\
\text { Renaudin et al. }(2004)\end{array}$ \\
\hline $\begin{array}{l}\text { Kuzel's salt } \\
{\left[\mathrm{Ca}_{4} \mathrm{Al}_{2}(\mathrm{OH})_{12}\right]\left[\mathrm{Cl}\left(\mathrm{SO}_{4}\right)_{0.5} \cdot 5 \mathrm{H}_{2} \mathrm{O}\right]}\end{array}$ & $\begin{array}{l}R \overline{3} \\
a=5.7708(2) \\
c=50.418(3)\end{array}$ & Mesbah, François et al. (2011) \\
\hline $\begin{array}{l}\text { Kuzelite } \\
{\left[\mathrm{Ca}_{4} \mathrm{Al}_{2}(\mathrm{OH})_{12}\right]\left[\mathrm{SO}_{4} \cdot 6 \mathrm{H}_{2} \mathrm{O}\right]}\end{array}$ & $\begin{array}{l}R \overline{3} \\
a=5.76(1) \\
c=53.66(2)\end{array}$ & Pöllmann et al. (1997) \\
\hline $\begin{array}{l}\text { Iodoaluminate } \\
{\left[\mathrm{Ca}_{4} \mathrm{Al}_{2}(\mathrm{OH})_{12}\right]\left[2 \mathrm{I} \cdot 4 \mathrm{H}_{2} \mathrm{O}\right]}\end{array}$ & $\begin{array}{l}R \overline{3} \\
a=5.772(1) \\
c=26.538(1)\end{array}$ & Rapin et al. (1999) \\
\hline $\begin{array}{l}\text { Nitroaluminate } \\
{\left[\mathrm{Ca}_{4} \mathrm{Al}_{2}(\mathrm{OH})_{12}\right]\left[\left(\mathrm{NO}_{3}\right)_{2} \cdot 4 \mathrm{H}_{2} \mathrm{O}\right]}\end{array}$ & $\begin{array}{l}P \overline{3} c 1 \\
a=5.7445(8) \\
c=17.235(5)\end{array}$ & Renaudin \& François (1999) \\
\hline
\end{tabular}

the calcium hemicarboaluminate $(\mathrm{Hc})$ phase, has not been reported so far. This phase is important because it is the main phase formed at the beginning of carbonation reactions of building materials. The chemical formula of this compound can be written as

$$
\left[\mathrm{Ca}_{4} \mathrm{Al}_{2}(\mathrm{OH})_{12}\right]\left[\mathrm{OH}\left(\mathrm{CO}_{3}\right)_{0.5} \cdot n \mathrm{H}_{2} \mathrm{O}\right] \text {, }
$$

where the amount of water molecules $(n)$ can vary and have different bonding fashions. Another common way of representing the composition of the Hc phase (especially in industry) is by using the cement chemistry notation

$$
\mathrm{C} 3 A \cdot \frac{1}{2} \mathrm{Ca}(\mathrm{OH})_{2} \cdot \frac{1}{2} \mathrm{CaCO}_{3} \cdot x \mathrm{H}_{2} \mathrm{O} .
$$

Pioneering studies on the Hc phase were reported in the 1960s, i.e. those by Dosch \& zur Strassen (1965), Ahmed et al. (1968) and Roberts (1968). Fischer \& Kuzel (1982) reinvestigated the system 20 years later and indexed the powder diffraction pattern in the trigonal crystal system, with the space group being either $R 3 c$ or $R \overline{3} c$ and lattice parameters of $a=5.77$ and $c=49.16 \AA$. The crystal structure was not solved but it was proposed that it is built of typical AFm main layers and an interlayer composed of the carbonate anion, hydroxyl anions and two types of water molecules - crystallographically bonded and space-filling water molecules. Ipavec et al. (2011) reported that \& François, 1999), sulfate, as in the synthesized monosulfoaluminate (Allmann, 1977) or as in the natural mineral kuzelite (Pöllmann et al., 1997), chloride as in Friedel's salt (Terzis et al., 1987; Renaudin, Kubel et al., 1999; Rapin et al., 2002), iodide (Rapin et al., 1999), nitrate (Renaudin \& François, 1999) and others. Several structural studies on binary phases, $\left[X_{x} Y_{y} \cdot n \mathrm{H}_{2} \mathrm{O}\right]^{2-}$, were reported. In these structures $X$ and $Y$ can be sulfate and chloride as in Kuzel's salt (Mesbah, François et al., 2011), chloride and carbonate as in the synthesized phase (Mesbah, Rapin et al., 2011) or as in the natural mineral hydrocalumite (Sacerdoti \& Passaglia, 1988), bromide and chloride (Rapin \& Francois, 2001; Renaudin et al., 2004) or hydroxide and carbonate (Fischer \& Kuzel, 1982). Also, examples of a ternary AFm phase containing sulfate, carbonate and hydroxide as anions are reported (Pöllmann et al., 1998; Pöllmann, 2006). Most of the crystal structures of the AFm phases are solved and refined using single-crystal or powder X-ray diffraction data. A list of selected AFm phases, described in the trigonal (rhombohedral) crystal system (as the crystal structures of the compounds presented in this article), is given in Table 1 .

To the best of our knowledge the crystal structure of the binary phase composed of hydroxide and carbonate anions, the Hc phase shows high susceptibility to atmospheric carbon dioxide and when exposed to air it gradually transforms into calcium monocarboaluminate (which structure was solved by François et al., 1998; Renaudin \& François, 1999).

The Hc phase does not form crystals of sufficient quality for single-crystal diffraction. Accordingly, the only method of choice for structure determination is powder diffraction.

Motivated by the importance of the Hc phase in the cement industry, structural studies on the system in the temperature range $297-1173 \mathrm{~K}$ were undertaken. This phase was synthesized as the (sufficiently) pure phase and was studied using synchrotron X-ray powder diffraction (XRPD). The crystal structure of the Hc phase was solved and refined. At room temperature, together with the Hc phase, another major phase was found in the system, the carbonated calcium hemicarboaluminate $(\mathrm{cHc})$ phase. Its structure was solved and refined and it was found that this phase is characterized by a larger amount of carbonate anion (at the expense of the hydroxyl anions). By heating in an atmosphere with a reduced amount of carbon dioxide, the Hc phase completely transforms into the cHc phase which thereafter is stable up to decomposition. The high-temperature behavior of the twophase system (referred as Hc-cHc) was studied by in situ high- 
Table 2

Chemical analysis of the synthesized $>\mathrm{Hc}-\mathrm{cHc}$ sample.

The theoretical values are calculated for a hemicarboaluminate phase with 11.5 water molecules (also counting the space-filling water molecules) with small impurities of tricalcium dialuminium oxide hexahydrate and calcium carbonate included.

\begin{tabular}{lll}
\hline & Theoretical (\%) & Measured (\%) \\
\hline $\mathrm{CaO}$ & 39.75 & 39.2 \\
$\mathrm{Al}_{2} \mathrm{O}_{3}$ & 18.07 & 19.2 \\
$\mathrm{CO}_{2}$ & 3.90 & \\
$\mathrm{H}_{2} \mathrm{O}$ & 38.28 & 41.9 \\
$\mathrm{Sum}$ & 100 & 100.3 \\
\hline
\end{tabular}

resolution synchrotron X-ray powder diffraction and microRaman spectroscopy.

\section{Experimental}

\subsection{Synthesis}

The Hc-cHc sample was synthesized using a paste reaction with stoichiometric quantities of monocalcium aluminate (synthesized by the laboratory reaction of $\mathrm{CaCO}_{3}$ and $\gamma$ $\mathrm{Al}_{2} \mathrm{O}_{3}$ with intermediate grinding at a temperature of $1623 \mathrm{~K}$ ), $\mathrm{CaO}$ (synthesized by decarbonization reaction of $\mathrm{CaCO}_{3}$ at $1273 \mathrm{~K}$ for $1 \mathrm{~h}$ ) and $\mathrm{CaCO}_{3}$. The reactants were mixed in polyethylene bottles with $\mathrm{CO}_{2}$-free, freshly distilled water (with a water-to-solid ratio of 10). Chemical analyses were performed using ICP-OES (HORIBA) and ICP-MS (thermoinstruments PQ Excell) and the results are given in Table 2. By using XRPD analysis two impurities (tricalcium dialuminium oxide hexahydrate and calcium carbonate) were identified, together present in less than $4 \mathrm{wt} \%$ of the composition. After drying in a desiccator at room temperature the Hc-cHc system crystallized as thin hexagonal uniaxial negative plates (as previously observed by Fischer \& Kuzel, 1982). The scanning electron micrograph of the phase at room temperature is given in Fig. 1 (obtained by using a Jeol instrument JSM 6300).

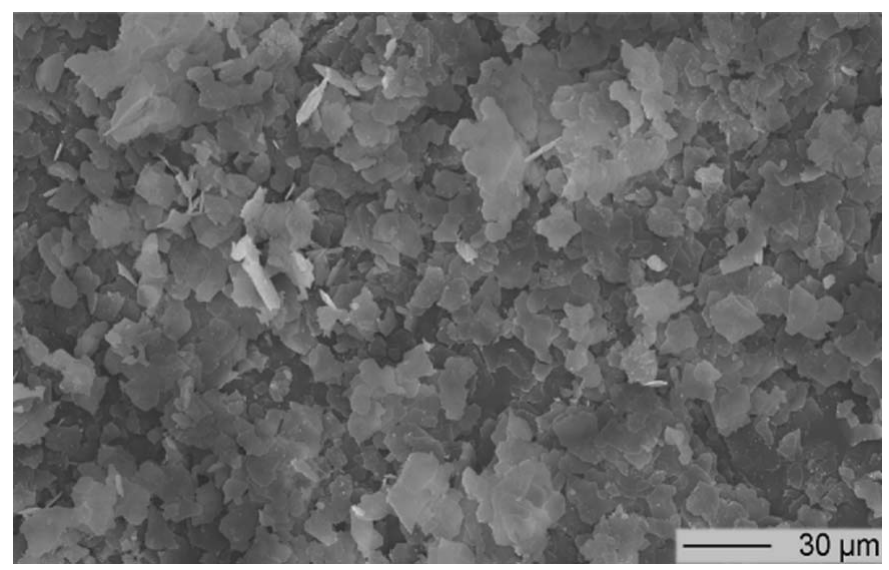

Figure 1

Scanning electron micrograph of Hc-cHc powder.

\subsection{Powder X-ray diffraction and crystal structure determi- nation}

For crystal structure determination the powder diffraction data of Hc-cHc (Fig. 2) were collected using a high-resolution powder diffractometer at the I11 beamline, located at the British national synchrotron facility the Diamond Light Source. The wavelength of radiation was determined from a silicon standard to be 0.826401 (300) $\AA$. The beamline set-up and characteristics are described in the literature (Parker et al., 2011; Thompson et al., 2009, 2011). The diffraction data were collected in the temperature range $297-1173 \mathrm{~K}$. The scans at each temperature were written continuously with $2 \mathrm{~K} \mathrm{~min}^{-1}$ and $14 \mathrm{~s}$ per frame.

For the diffraction measurements finely powdered samples were placed in quartz capillaries with limited contact to the atmosphere. The carbon dioxide led to the transformation of the Hc phase into the $\mathrm{cHc}$ phase on heating, as shown by the changes in unit-cell parameters in Fig. 2. In the case of heating the Hc-cHc system in open air, the system shows significantly different behavior, i.e. resulting in the appearance of a new phase at higher temperatures (further studies on this phase transformations are in process).

Analysis of the powder data collected at $297 \mathrm{~K}$ led to the identification of two major phases, $\mathrm{Hc}$ and $\mathrm{cHc}$, and impurities of $\mathrm{H}_{12} \mathrm{Al}_{2} \mathrm{Ca}_{3} \mathrm{O}_{12}$ (16592-ICSD) and $\mathrm{CaCO}_{3}$ (20179-ICSD), both impurity phases present in less than $4 \mathrm{wt} \%$ of the total amount. Both AFm phases were indexed (Coelho, 2003) in the trigonal crystal system with slightly different unit-cell parameters, as given in Table 3 . $^{\mathbf{1}}$

The extinctions found in the powder pattern indicated $R \overline{3} c$ as the most probable space group, and this was later confirmed by Rietveld refinement (Rietveld, 1969). The peak profiles and precise lattice parameters were determined by a Pawley fit (Pawley, 1981) using the fundamental parameter approach of TOPAS4.2 (Bruker, 2007; Cheary et al., 2004; Coelho, 2000). Chebyshev polynomials were used for the modeling of the background. The same procedure was repeated on the data collected at different temperatures. By increasing the temperature, gradual changes of the unit cell parameters were noticed and above $337 \mathrm{~K}$ only one major phase was identified (cHc), as shown in Fig. 2.

Over the course of the crystal structure solution the atomic coordinates of the main layer atoms were taken from the close structure (Mesbah, Rapin et al., 2011) as a starting model. In order to confirm the structure of the layers without using a starting model, the charge-flipping method was used, leading to the same crystal structure. The solution was completed by finding the structure of the interlayer region, performed by inspecting the difference Fourier maps.

For the final Rietveld refinement, the profile and lattice parameters as well as the atomic positions were subjected to refinement except of the parameters of the hydroxyl $\mathrm{O}$ atoms

\footnotetext{
${ }^{1}$ Supplementary data for this paper are available from the IUCr electronic archives (Reference: EB5017). Services for accessing these data are described at the back of the journal.
} 
because of the low occupancies. The displacement factors were treated isotropically.

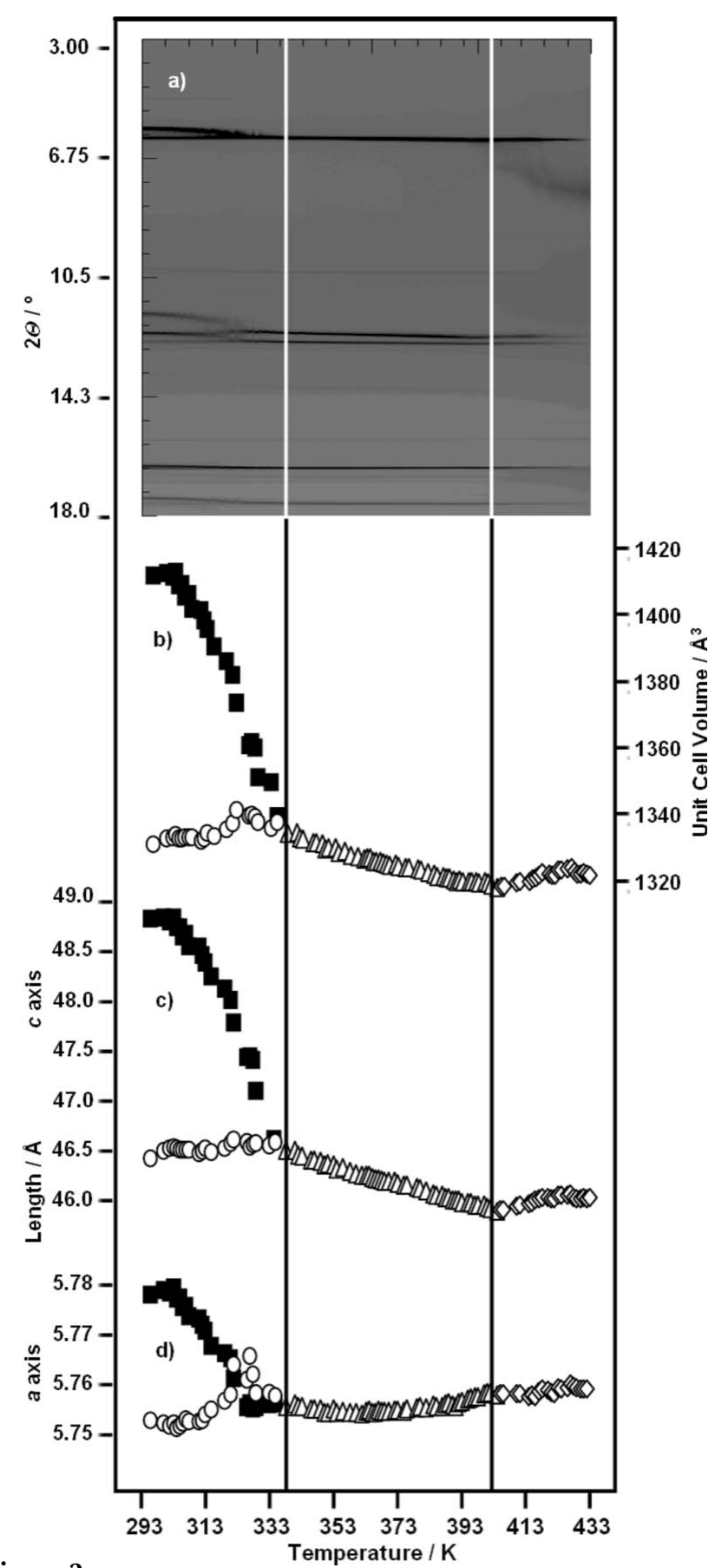

Figure 2

(a) Two-dimensional projection (simulated heating-Guinier pattern) of the observed scattered X-ray intensity for the Hc-cHc system as a function of temperature and diffraction angle. The two-dimensional plot was prepared using the Powder3D suite (Hinrichsen et al. 2006). The changes of the values of $(b)$ the unit-cell volume, $(c)$ the $c$ axis and $(d)$ the $a$ axis are plotted against temperature. The values of the unit-cell parameters are obtained by Pawley refinement of the diffraction patterns. The first vertical line shows the temperature point above which only the cHc phase is observed, and the second one indicates the onset of amorphization (solid symbols refer to the Hc phase, open symbols refer to the $\mathrm{cHc}$ phase).
Table 3

Crystallographic and Rietveld refinement data for calcium hemicarboaluminate-carbonated calcium hemicarboaluminate system.

At $297 \mathrm{~K}$ two phases ( $\mathrm{Hc}$ and $\mathrm{cHc}$ ) are present, whereas at $347 \mathrm{~K}$ the sample is composed of one phase $(\mathrm{cHc})$. The crystal structure used for the refinement of $\mathrm{cHc}$ is not complete (see $\S 3$ ).

\begin{tabular}{ll}
\hline Compound name & Calcium carboaluminate hydrate \\
Molecular formula & {$\left[\mathrm{Ca}_{4} \mathrm{Al}_{2}(\mathrm{OH})_{12}\right]\left[\mathrm{OH}_{2 n}\left(\mathrm{CO}_{3}\right)_{1-n} \cdot 4 \mathrm{H}_{2} \mathrm{O}\right]$} \\
Space group & $R \overline{3} c$ \\
$Z$ & 6 \\
Wavelength $(\AA)$ & $0.826401(300)$ \\
Starting angle $\left({ }^{\circ} 2 \theta\right)$ & 3 \\
Final angle $\left({ }^{\circ} 2 \theta\right)$ & 61.5 \\
Data collection $\left(\mathrm{K} \mathrm{min}^{-1}\right)$ & 2 \\
Data collection (s per frame) & 14
\end{tabular}

\begin{tabular}{llll}
\hline & $\mathrm{Hc}$ & $\mathrm{cHc}$ & $\mathrm{cHc}$ \\
\hline Temperature $(\mathrm{K})$ & 297 & 297 & 347 \\
Weight amount $\dagger(\%)$ & 62.6 & 33.8 & 97.5 \\
$n \ddagger$ & 0.5 & 0.2 & 0.2 \\
Formula weight $\left(\mathrm{g} \mathrm{mol}^{-1}\right) \ddagger$ & 537.50 & 545.29 & 545.29 \\
$a(\AA)$ & $5.7757(1)$ & $5.7491(1)$ & $5.7534(1)$ \\
$c(\AA)$ & $48.812(2)$ & $46.347(4)$ & $46.389(1)$ \\
$V\left(\AA^{3}\right)$ & $1410.14(7)$ & $1326.65(9)$ & $1329.84(4)$ \\
$R_{\mathrm{Bragg}} \S$ & 2.181 & 1.106 & 3.845 \\
$R_{\exp } \S$ & 0.773 & & 0.784 \\
$R_{\mathrm{p}} \S$ & 2.869 & & 2.971 \\
$R_{\mathrm{wp}} \S$ & 4.043 & & 4.961 \\
$S \S$ & 5.233 & & 6.329 \\
No. of variables & 166 & & 104 \\
\hline
\end{tabular}

$\dagger$ The sample contained impurities of two other phases (tricalcium dialuminium oxide hexahydrate, 16592-ICSD, and calcium carbonate, 20179-ICSD) with quantities less than $4 \%$, for the impurities the unit cell axes, crystal size, strain and displacement parameters were subject to refinement (no. of variables 7 and 8 ). \$ Due to the small disordered occupancies of the hydroxyl $\mathrm{O}$ atoms, they are not included in the final refinement of the $\mathrm{cHc}$ phase. Therefore, the presented values of $n$ and of the formula weight are calculated. $\quad \S R_{\text {exp }}, R_{\mathrm{p}}, R_{\mathrm{wp}}, R_{\mathrm{Bragg}}$ and $S$ values are as defined in TOPAS4.2 (Bruker, 2007)

The strong anisotropy of width and asymmetry of the Bragg reflections could be quite satisfactorily modeled by the phenomenological microstrain model of Stephens with four refinable parameters for the rhombohedral space group (Stephens, 1999). Nevertheless, in order to obtain a better fit of the peak profile for a higher quality refinement of the crystal structure, symmetry-adapted spherical harmonics were applied instead to the width and shape of the Bragg peaks. No attempt was made to physically model the complex peak shape, suggesting a severe stacking fault and other types of disorder. Despite the use of capillaries in Debye-Scherrer geometry, a small amount of the preferred orientation was detected which originates from the plate-like form of the crystallites (see Fig. 1) and was adequately described by the use of symmetry-adapted spherical harmonics. The origin of the complex peak profile is quite likely related to the simultaneous occurrence of stacking faults (h.c.p./c.c.p.) of the extreme layer structure and variations of the content of dissipated water in different domains. Rietveld refinements were carried out on the diffraction patterns collected at 297 and $347 \mathrm{~K}$ (Fig. 3). The refinement data and the final agreement factors ( $R$ values) are listed in Table 3.

The difference Fourier maps were generated using the program JANA (Petřiček et al., 2006). The structure factors for 

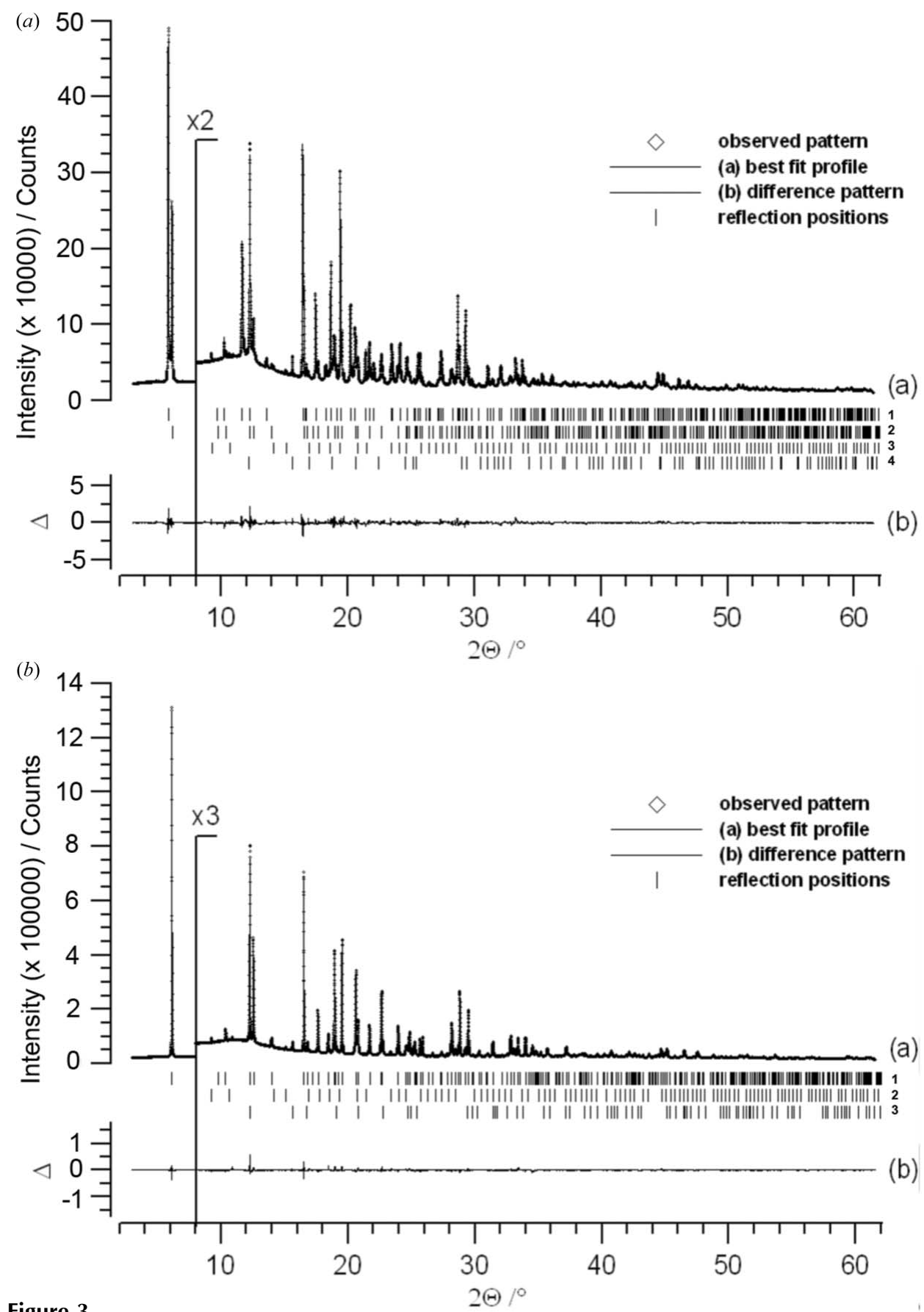

Figure 3

Scattered X-ray intensities of the Hc phase as a function of diffraction angle. The observed pattern (diamonds) measured in Debye-Scherrer geometry, the best Rietveld fit profile (line) and the difference curve between the observed and calculated profiles (below) are shown. (a) The pattern collected at $297 \mathrm{~K}$ contains two major phases, $\mathrm{Hc}$ and $\mathrm{cHc}$, and impurities of $\mathrm{H}_{12} \mathrm{Al}_{2} \mathrm{Ca}_{3} \mathrm{O}_{12}$ and $\mathrm{CaCO}_{3}$ (reflection positions $1,2,3,4$ respectively). (b) At $347 \mathrm{~K}$ only one major phase is present, $\mathrm{cHc}$ and impurities of $\mathrm{H}_{12} \mathrm{Al}_{2} \mathrm{Ca}_{3} \mathrm{O}_{12}$ and $\mathrm{CaCO}_{3}$ (reflection positions $1,2,3$, respectively).

Fourier synthesis were obtained from the Rietveld refinement using the program TOPAS4.2 (Bruker, 2007).

\subsection{Raman spectroscopy}

The micro-Raman spectra were recorded using a Jobin Yvon Typ V 010 Labram single grating spectrometer, equipped with a double super razor edge filter and a peltiercooled CCD camera. The resolution of the spectrometer (grating $1800 \mathrm{~L} \mathrm{~mm}^{-1}$ ) was 1 Raman shift $\left(\mathrm{cm}^{-1}\right)$. The spectra were taken in quasi-backscattering geometry using the linearly polarized $532.0 \mathrm{~nm}$ line of a diode laser with power less than $1 \mathrm{~mW}$, focused to a $20 \mu \mathrm{m}$ spot through a $20 \times$ microscope objective onto the top surface of the sample. For the heating experiments, a linkam THS 600 heater was used, with a small argon gas flow rate.

\section{Results and discussion}

\subsection{Crystal structure of $\mathrm{Hc}$}

The crystal structure of the Hc phase (Fig. 4) is composed of main layers and interlayers, as in the case of other AFm phases. The structure of the main layers is typical for the AFm family, where the aluminium is coordinated by six $\mathrm{O}$ atoms forming an octahedron. Aluminium octahedra are arranged in hexagonal primitive nets connected by the $\mathrm{Ca}$ atoms (Fig. 4a). The calcium cation is coordinated by seven $\mathrm{O}$ atoms, six belonging to the main layer and an oxygen from the water molecule placed in the interlayer region. The seven $\mathrm{O}$ atoms around the calcium build a polyhedron that can be regarded as a strongly deformed octahedron with one triangle expanded such that a bowl is formed and is closed by an interlayer water molecule forming a capped trigonal antiprism (Terzis et al., 1987), as shown in Fig. 4(b). Six main layers arranged perpendicular to the $c$-axis and divided by the interlayer regions build the packing diagram of the Hc phase, as presented in Fig. 4(c).

The main structural differences within the members of the AFm family are observed in their interlayer regions. In the case of the Hc phase, the interlayer is composed of carbonate and hydroxyl anions and water molecules which are bonded to the calcium cations of the main layer (Fig. 4c). On every aluminium cation in the main layer there are 0.25 carbonate 
and 0.5 hydroxyl anions in the interlayer region, providing electroneutrality. The carbonate anions are ordered and placed perpendicular to the threefold axis running parallel to the $c$ axis. The hydroxyl anions are placed on a general position and are disordered around the position of the carbonate anion. Owing to the low occupancy and high level of disorder, the positions of the hydroxyl group cannot be freely refined. In order to find the most probable positions of these atoms difference Fourier maps were generated using a model of the crystal structure containing the main layers, the bonded water molecules in the interlayer and the carbonate group with a fixed occupancy of 0.25 . Two different sections of the map are given in Fig. 5. On closer inspection of the map neither positive nor negative electron density can be observed around the
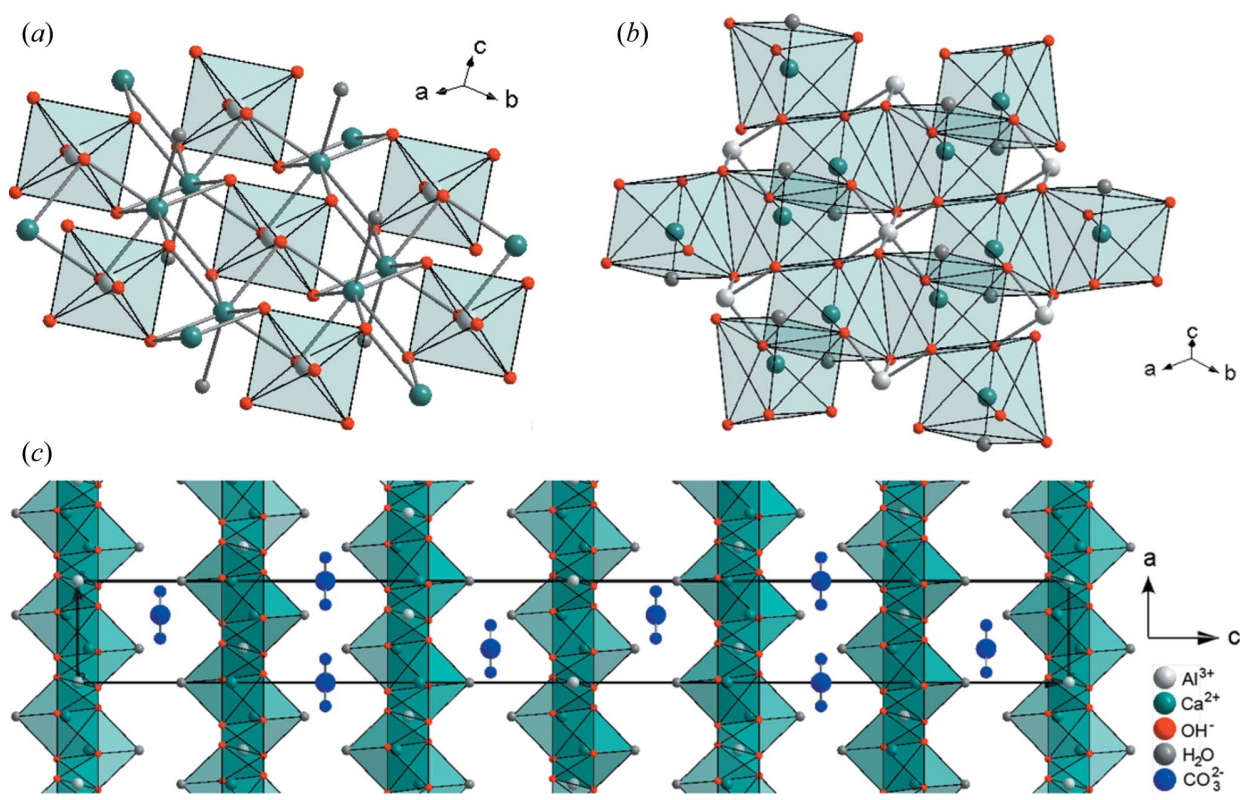

Figure 4

Crystal structure of the Hc phase main layers featuring $(a)$ the aluminium octahedra and $(b)$ the calciumcapped trigonal antiprisms. (c) Packing diagram of the Hc phase in the viewing direction of the $b$ axis. In the interlayer region the carbonate group and the crystallographically bonded water molecules are presented, whereas the interlayer $\mathrm{OH}^{-}$group is omitted for clarity. The unit cell is outlined with solid lines.

$(a)$

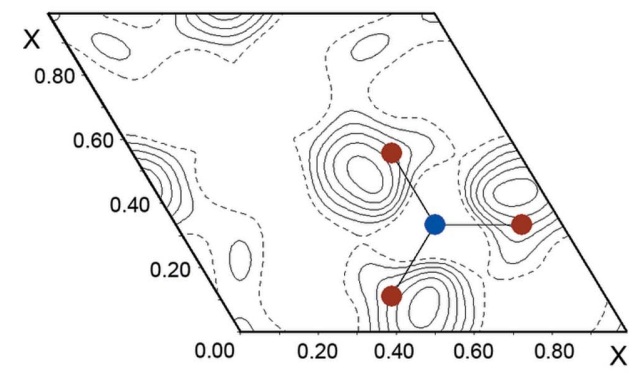

Figure 5

Two-dimensional difference Fourier electron-density maps of the Hc phase. Positive contour levels from 0 e $\AA^{-3}$, step 0.03 e $\AA^{-3}$; negative contour levels at 0 e $\AA^{-3}$. (a) Projection perpendicular to the $z$ axis $(z=$ 0.095 ), the carbonate group (carbon in blue, oxygen in red) imposed in the projection at $z=0.083$. (b) Projection perpendicular to the $y$ axis $(y=0.000)$. position of the $\mathrm{C}$ atom, implying the correctly refined occupancy of the carbonate group. Fig. 5(a) shows that the positive electron density is observed above and below the positions of the carbonate group originating by the $\mathrm{OH}^{-}$anion. By introducing the hydroxyl anions in the model, a significant reduction in the $R_{\mathrm{wp}}$ factor was noticed (dropping by a value of $2 \%$ ). During the final Rietveld refinement the position and occupancy of the $\mathrm{OH}-$ group was fixed, as found by the difference Fourier maps. It is worth noting that the difference Fourier map calculated after introducing the $\mathrm{OH}^{-}$anion still showed a positive electron density smeared below and above the carbonate group. This electron density might originate from dissipated water, completely disordered in this interlayer's region as suggested by previous studies. Namely, Fischer \& Kuzel (1982) reported different hydration stages of the $\mathrm{Hc}$ phase in the temperature range between 295 and $473 \mathrm{~K}$. As mentioned in $\$ 1$, it was suspected that in the interlayer region, beside the water molecules bonded to the calcium cations, there are space-filling water molecules. In their study the content of water is removed in three steps: the first two steps are assigned to losing the space-filling molecules, and the third step to removing the crystallographically bonded water. The space-filling water cannot be detected by $\mathrm{X}$ ray diffraction, therefore it was not accounted for in the final Rietveld refinements and it was not included in the crystal structure model.

Taking into account the disorder of the anionic species in the structure, and their statistical distribution, it can be said that the local symmetry of the crystal structure is significantly lower $(C 1$ or $C i$ in Schoenflies notation).

\subsection{Crystal structure of $\mathbf{c H c}$ phase}

The $\mathrm{cHc}$ phase crystallized together with $\mathrm{Hc}$ giving the Hc$\mathrm{cHc}$ two-phase system. On heating, the whole quantity of $\mathrm{Hc}$ transferred into the $\mathrm{cHc}$ phase (Fig. 2). Both phases have the same crystal structure for the main layers, but they show a significant difference in the interlayer region. A difference Fourier 
(a)

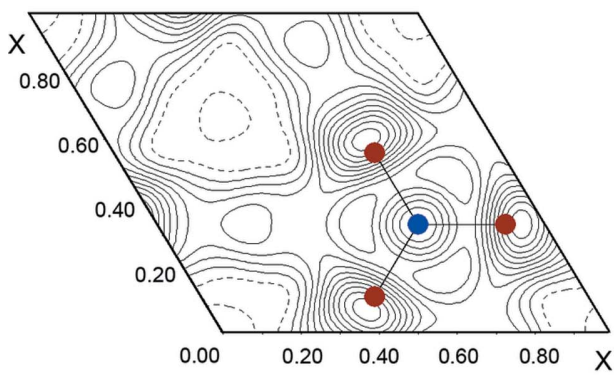

Figure 6

Two-dimensional difference Fourier electron-density maps of the cHc phase. Positive contour levels from 0 e $\AA^{-3}$, step 0.03 e $\AA^{-3}$; negative contour levels at 0 e $\AA^{-3}$. (a) Projection perpendicular to the $z$ axis $(z=$ 0.083 ), the carbonate group (carbon in blue, oxygen in red) is imposed on the projection at $z=0.083$. (b) Projection perpendicular to the $y$ axis $(z=0.000)$.

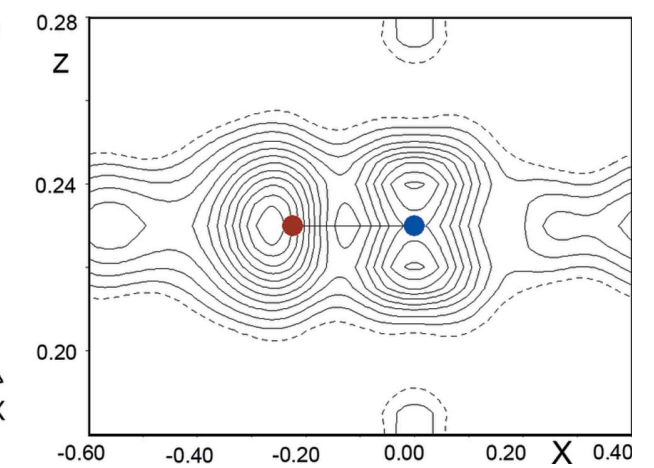

attributed to the carbonate group directly bonded to the main layer and the Raman band at $1086 \mathrm{~cm}^{-1}$ is attributed to the weakly bonded carbonate group located at the center of the interlayer. The micro-Raman spectra of the Hc-cHc system are presented in Fig. 7, where an intense band is noticed around $1086 \mathrm{~cm}^{-1}$ corresponding to the non-bonded carbonate group. The micro-Raman spectra were taken at different temperatures and a shift of the band was not observed, confirming that in the structures of both phases ( $\mathrm{Hc}$ and

map was generated using the same model as in the case of the Hc phase (containing the main layers, the interlayer water molecules and the carbonate group with fixed occupancy of 0.25 ). Closer inspection of the map showed pronounced positive electron density around the positions of the carbonate atoms, indicating the underestimated content of the carbonate group (Fig. 6). After refining the occupancies of the carbonate atoms to the value of 0.4 the difference Fourier map showed no significant (neither positive nor negative) electron density around the carbonate atoms. As shown in Fig. 6(b), the carbonate group is shifted up and down from the position in the center of the interlayer, which also implies that the local symmetry might be as low as $C 1$ or $C i$, and the resulting trigonal structure is obtained as the superposition of all interlayers. According to the charge balance, the quantity of hydroxyl anions has to be reduced and fixed to 0.2. Taking into account the low occupancy and the fact that these hydroxyl atoms are distributed on a general position with high multiplicity, their positions cannot be found and refined from powder diffraction data. To shine light on the interlayer structure and obtain deeper knowledge on the distribution of the anionic species, additional studies using the method of maximum entropy are in progress.

cHc can be regarded as an intermediate phase between the Hc phase and calcium monocarboaluminate (abbreviated as $\mathrm{Mc})$. The Mc phase crystallizes in the triclinic crystal system and one of the main differences with the crystal structure of the Hc phase is the fact that one of the $\mathrm{O}$ atoms from the carbonate group is directly bonded to the calcium cation (François et al., 1998).

\subsection{Micro-Raman spectroscopy}

A powerful tool to inspect the bonding scheme of the carbonate group in AFm phases is micro-Raman spectroscopy. As described above, in the case of the $\mathrm{Hc}$ and $\mathrm{cHc}$ phases, the carbonate group is placed in the center of the interlayer and the $\mathrm{O}$ atoms are not bonded to the main layer. Mesbah, Rapin et al. (2011) reported the micro-Raman spectra of some AFm phases and found that the Raman band at $1068 \mathrm{~cm}^{-1}$ is
$\mathrm{cHc}$ ) the carbonate group environment is the same. It should be noted that an additional band is noticed at $1068 \mathrm{~cm}^{-1}$, corresponding to the bonded carbonate group. During the micro-Raman measurements only the surface is tested, therefore, it can be suspected that part of the surface of Hc$\mathrm{cHc}$ is transformed into Mc, giving rise to this weak band. The same experiment was carried out on an open atmosphere with unlimited access to carbon dioxide and under these experimental conditions at higher temperatures the band at $1086 \mathrm{~cm}^{-1}$ completely disappeared and the band at $1068 \mathrm{~cm}^{-1}$ gained in intensity, indicating that a new phase was formed where the carbonate group is bonded to the main layer (crystal structure analysis of this phase is in progress). As shown in Fig. 7, the position of the band at $530 \mathrm{~cm}^{-1}$ remains unchanged. Knowing that this band originates by the Raman active vibrations of the $\mathrm{Al}(\mathrm{OH})_{6}$ group, it can be confirmed that in the temperature interval up to $388 \mathrm{~K}$ the structure of the main layers remains unchanged.

\subsection{Decomposition products}

Analysis of the powder patterns collected as a function of temperature led to the detection of two phases crystallizing

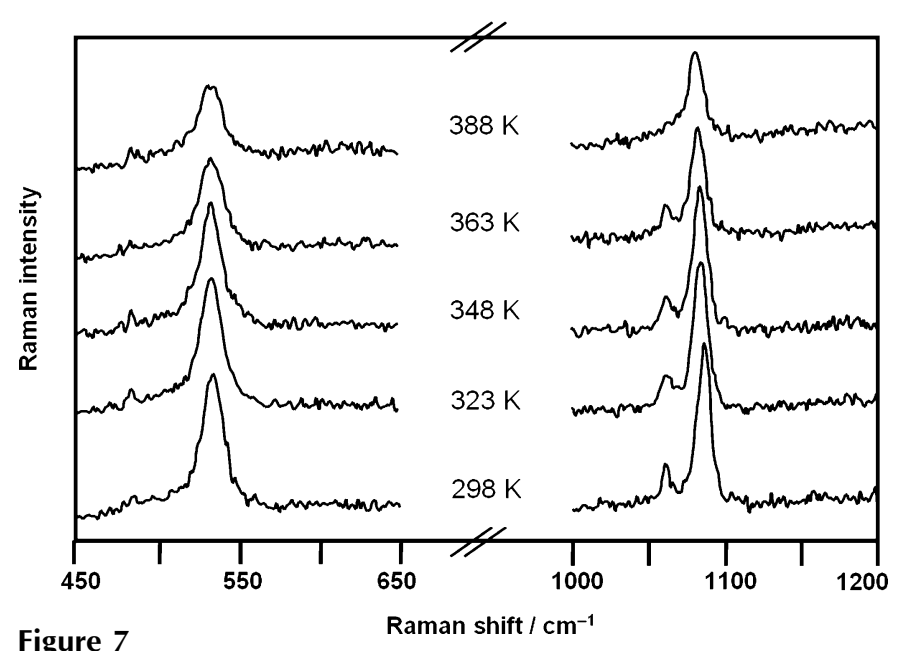

Micro-Raman spectra of the Hc-cHc system. 
after the decomposition of the Hc-cHc system. The first phase, lime (CaO, PDF file 43-1001), appeared with onset at $823 \mathrm{~K}$, and the second one, mayenite $\left(\mathrm{Ca}_{12} \mathrm{Al}_{14} \mathrm{O}_{33}\right.$, PDF file 48-1882), with onset at $1123 \mathrm{~K}$. The decomposition is similar in the case of Kuzel's salt (Mesbah, François et al., 2011).

\section{Conclusion}

The crystal structure of the cementitious Hc AFm phase was solved and refined by XRPD using synchrotron radiation. It was found that up to $c a 338 \mathrm{~K}$ two different hydration forms simultaneously exist, the $\mathrm{Hc}$ and the $\mathrm{cHc}$ phase. Their crystal structures are composed of positively charged main layers and negatively charged interlayers. The interlayer region accommodates statistically distributed carbonate and hydroxyl anions. In the $\mathrm{Hc}$ phase on every $\mathrm{Al}$ atom there are 0.25 carbonate anions and 0.5 hydroxyl anions. By partial carbonation of the Hc phase, the $\mathrm{cHc}$ phase is formed in which there are more carbonate anions (0.4) and less hydroxyl anions (0.2). On increasing the temperature in atmosphere with a reduced amount of carbon dioxide the Hc phase completely transforms into the $\mathrm{cHc}$ phase which is present up to decomposition at $c a 393 \mathrm{~K}$. The carbonate group environment was additionally studied by micro-Raman spectroscopy and it was confirmed that in both structures the carbonate group is placed in the interlayer region.

The authors thank the Diamond Light Source for the synchrotron beam time and the assistance of F. Adams, Dr L. Vella-Zarb, Dr J. E. Parker and Dr C. C. Tang during the measurements. A. Schulz is gratefully acknowledged for measuring the micro-Raman spectra. TR acknowledges the PhD scholarship given by the IMPRS-AM.

\section{References}

Ahmed, S. J., Dent Glasser, L. S. W. \& Taylor, H. F. W. (1968). Proc. 5th Int. Symp. Chem. Cement, Vol. II, p. 118, Tokyo.

Allmann, R. (1977). Neues Jahrb. Miner. Monatsh. 3, 136-144.

Bruker (2007). TOPAS, Version 4.2. Bruker AXS, Karlsruhe, Germany.

Cheary, R. W., Coelho, A. A. \& Cline, J. P. (2004). J. Res. Natl Inst. Stand. Technol. 109, 1-25.

Coelho, A. A. (2000). J. Appl. Cryst. 33, 899-908.

Coelho, A. A. (2003). J. Appl. Cryst. 36, 86-95.

Dosch, W. \& zur Strassen, H. (1965). Zement-Kalk-Gips, 5, 233.
Fischer, R. \& Kuzel, H. J. (1982). Cem. Concr. Res. 12, 517-526.

François, M., Renaudin, G. \& Evrard, O. (1998). Acta Cryst. C54, 1214-1217.

Hinrichsen, B., Dinnebier, R. E. \& Jansen, M. (2006). Z. Kristallogr. 23, 231-236.

Ipavec, A., Gabrovšek, R., Vuk, T., Kaučič, V., Maček, J. \& Meden, A. (2011). J. Am. Ceram. Soc. 94, 1238-1242.

Matschei, T., Lothenbach, B. \& Gasser, F. P. (2007). Cem. Concr. Res. 37, 118-130.

Mesbah, A., François, M., Cau-dit-Coumes, C., Frizon, F., Filichuk, Y., Leroux, F., Ravaux, J. \& Renaudin, G. (2011). Cem. Concr. Res. 41, 504-509.

Mesbah, A., Rapin, J.-P., François, M., Cau-dit-Coumes, C., Frizon, F., Leroux, F. \& Renaudin, G. (2011). J. Am. Ceram. Soc. 94, 261-268.

Parker, J. E., Thompson, S. P., Cobb, T. M., Yuan, F., Potter, J., Lennie, A. R., Alexander, S., Tighe, C. J., Darr, J. A., Cockcroft, J. C. \& Tang, C. C. (2011). J. Appl. Cryst. 44, 102-110.

Pawley, G. S. (1981). J. Appl. Cryst. 14, 357-361.

Petřiček, V., Dušek, M. \& Palatinus, L. (2006). JANA2006. Institute of Physics, Prague, Czech Republic.

Pöllmann, H. (1984). Diploma Thesis, Erlangen, Germany (in German).

Pöllmann, H. (2006). Neues Jahrb. Mineral. Abh. 182, 173-181.

Pöllmann, H., Löns, J. F. \& Kraus, C. (1998). Ber. Der. Dt. Mineral. Ges. p. 219.

Pöllmann, H., Witzke, T. \& Kohler, H. (1997). Neues Jahrb. Mineral. Monatsh. pp. 423-432.

Rapin, J.-P. \& François, M. (2001). Acta Cryst. C57, 137-138.

Rapin, J.-P., Renaudin, G., Elkaim, E. \& François, M. (2002). Cem. Concr. Res. 32, 6369.

Rapin, J.-P., Walcarius, A., Lefevre, G. \& François, M. (1999). Acta Cryst. C55, 1957-1959.

Renaudin, G. \& François, M. (1999). Acta Cryst. C55, 835-838.

Renaudin, G., François, M. \& Evrard, O. (1999). Cem. Concr. Res. 29, 63-69.

Renaudin, G., Kubel, F., Rivera, J. P. \& François, M. (1999). Cem. Concr. Res. 29, 1937-1942.

Renaudin, G., Rapin, J.-P., Elkaim, E. \& François, M. (2004). Cem. Concr. Res. 34, 1845-1852.

Rietveld, H. M. (1969). J. Appl. Cryst. 2, 65-71.

Roberts, M. H. (1968). Proc. 5th Int. Symp. Chem. Cement, Vol. II, p. 104, Tokyo.

Sacerdoti, M. \& Passaglia, E. (1988). Neues Jahrb. Mineral. Abh. 10, 462-475.

Stephens, P. W. (1999). J. Appl. Cryst. 32, 281-289.

Terzis, A., Fillipakis, S., Kuzel, H. J. \& Bruzlaff, H. (1987). Z. Kristallogr. 181, 29-34.

Thompson, S. P., Parker, J. E., Marchal, J., Potter, J., Birt, A., Yuan, F., Fearn, R. D., Lennie, A. R., Street, S. R. \& Tang, C. C. (2011). J. Synchrotron Rad. 18, 637-648.

Thompson, S. P., Parker, J. E., Potter, J., Hill, T. P., Birt, A., Cobb, T. M., Yuan, F. \& Tang, C. C. (2009). Rev. Sci. Instrum. 80, 075107. 